\title{
Formação Inicial Docente em Questão: o PIBID na Licenciatura em Informática
}

\author{
Anna Raquel da S. Marinho', Francisco das Chagas da S. Júnior ${ }^{1}$, Givanaldo \\ Rocha de Souza ${ }^{1}$, Pauleany Simões de Morais ${ }^{1}$ \\ ${ }^{1}$ Instituto Federal de Educação, Ciência e Tecnologia do Rio Grande do Norte - IFRN \\ raquelmarinho.linfor@gmail.com, ffrancisco.junior, givanaldo.rocha, \\ pauleany.morais\} difrn.edu.br
}

\begin{abstract}
This paper aims to reflect the possibilities of actuation of PIBID fellows, as well as understand the specificities of Informatics Degree Course at public schools. PIBID fellows are students from Federal Institute of Education, Science and Technology of Rio Grande do Norte (IFRN), Campus Natal - North, acting on public schools in the northern area of Natal city, Rio Grande do Norte State. The research has been done through bibliographic review, as well as fellows' experience reports since 2010. It was observed that PIBID represents a significant opportunity to constitute teacher's knowledges necessary to educational practice of the students included in the programme.

Resumo. Este trabalho objetiva refletir sobre as possibilidades de atuação dos bolsistas do PIBID, bem como compreender as especificidades do Curso de Licenciatura em Informática na escola pública. Os bolsistas estão vinculados ao Instituto Federal de Educação, Ciência e Tecnologia do Rio Grande do Norte (IFRN), Campus Natal - Zona Norte, atuando em escolas públicas na Zona Norte da cidade de Natal - RN. A pesquisa foi realizada por meio de revisão bibliográfica, bem como do relato de experiência da atuação dos bolsistas desde o período de 2010. Observa-se que o PIBID representa uma significava oportunidade de constituição dos saberes docentes necessários à prática educativa dos Licenciandos inseridos no programa.
\end{abstract}

\section{Introdução}

A formação de professores vem sendo ao longo dos anos pauta de intensas discussões e debates em meio acadêmicos e na realidade cotidiana da escola pública. Nos anos 2000, instituiu-se o Programa Institucional de Bolsas de Iniciação à Docência (PIBID) pela Portaria n. 72, de 9 de abril de 2010, que fornece bolsas a estudantes das licenciaturas no sentido de oportunizar a estes a vivência da docência. Nesse caso, se faz necessário analisar uma concepção de formação inicial de professores e expor a realidade específica da Licenciatura em Informática na realidade da escola pública.

Nessa perspectiva, esse trabalho aborda as ações desencadeadas no PIBID em uma realidade específica no Curso de Licenciatura em Informática no Campus Natal Zona Norte do IFRN. Mostra-se a relevância do programa para a formação inicial dos professores na constituição dos saberes docentes necessários à atuação profissional. Sabe-se que de certa forma a escola pública brasileira não possui um profissional de Informática para articular as ações do programa de uma maneira contextualizada e necessária à iniciação da prática docente. Nesse caso, é relevante discutir a necessidade 
da formação inicial de professores, papel do PIBID nessa formação, bem como a experiência do programa em uma realidade específica.

\section{Significado do PIBID para a Formação dos Licenciandos}

Com a propagação de Instituições de Ensino Superior, mesmo com formações às vezes duvidosas, o acesso à graduação para os professores já em atuação vem sendo superado ao longo dos anos. No entanto, ainda vivenciam-se dificuldades no que concerne à qualidade da formação inicial de professores para a constituição dos saberes docentes desde o início da graduação.

Nos anos 2000, diante desse novo quadro de necessidades voltadas à formação inicial de professores da Educação Básica, foram definidas novas diretrizes estratégicas condutoras da política de formação. Nesse contexto, foi promulgado o Parecer CNE/CP 009/2001. Esse Parecer delimita as competências necessárias à formação docente, tendo como foco o saber fazer conduzido por uma lógica de mercado, sem significativas preocupações com o conhecimento científico, formação humana, ética e política do professor.

Com os contínuos debates sobre a formação de professores, tem-se constituída uma base nacional com diretrizes que deram origem à Política Nacional de Formação de Profissionais do Magistério da Educação Básica, por meio do Decreto n. 6755, de 29 de janeiro de 2009, que orienta a atuação da Coordenação de Aperfeiçoamento de Pessoal de Nível Superior (CAPES), na promoção de programas de formação inicial e continuada, e dá outras providências.

No tocante à busca desses objetivos, entre outras medidas, surgiu o Programa Institucional de Bolsas de Iniciação à Docência (PIBID), que é "uma iniciativa para o aperfeiçoamento e a valorização da formação de professores para a educação básica" [Brasil 2010], instituído pela Portaria n. 72, de 9 de abril de 2010. A finalidade do programa é fomentar a iniciação à docência de discentes da licenciatura plena das instituições de ensino superior federais, estaduais, municipais e comunitárias sem fins lucrativos, no intuito de estimular a formação dos educadores, valorizar o magistério e colaborar para a elevação da qualidade da educação básica. No ano de 2013, o Programa foi vinculado à LDB 9394/96, em que as ações vinculam o Ensino Superior à Educação Básica, de acordo com a portaria $\mathrm{n}^{\circ}$ 096, de 18 de julho de 2013, anexo I, art. $2^{\circ}$. Ainda segundo a mesma portaria, os objetivos do programa são:

I - incentivar a formação de docentes em nível superior para a educação básica;

II - contribuir para a valorização do magistério;

III - elevar a qualidade da formação inicial de professores nos cursos de licenciatura, promovendo a integração entre educação superior e educação básica;

IV - inserir os licenciandos no cotidiano de escolas da rede pública de educação, proporcionando-lhes oportunidades de criação e participação em experiências metodológicas, tecnológicas e práticas docentes de caráter inovador e interdisciplinar que busquem a superação de problemas identificados no processo de ensino aprendizagem;

V - incentivar escolas públicas de educação básica, mobilizando seus professores como co-formadores dos futuros docentes e tornando-as protagonistas nos processos de formação inicial para o magistério; 
CBIE-LACLO 2015

Anais do XXI Workshop de Informática na Escola (WIE 2015)

VI - contribuir para a articulação entre teoria e prática necessárias à formação dos docentes, elevando a qualidade das ações acadêmicas nos cursos de licenciatura;

VII - contribuir para que os estudantes de licenciatura se insiram na cultura escolar do magistério, por meio da apropriação e da reflexão sobre instrumentos, saberes e peculiaridades do trabalho docente [Brasil 2013].

Diante das ações delimitadas no Programa, as bolsas concedidas aos alunos da licenciatura têm o intuito de vinculá-los a um projeto de iniciação à docência. É uma iniciativa para aperfeiçoamento e valorização da formação inicial de professores, inserindo alunos da Licenciatura no contexto das escolas públicas, desde o início de sua formação acadêmica, para que eles desenvolvam atividades didático-pedagógicas sob orientação de um docente da licenciatura e um professor da escola. Canan (2012, p. 35) demonstra uma avaliação significativa sobre a atuação dos bolsistas participantes do PIBID:

[...] o programa constitui uma das alternativas para fortalecer a formação inicial na área das licenciaturas, considerando as conexões entre os diversos saberes, principalmente entre aqueles propiciados pela universidade e pela experiência em sala de aula, sendo que os bolsistas participantes entram em contato com a realidade vivenciada por professores da educação básica, desde o início de seus cursos. Dessa forma, a formação acadêmica passa a ser o primeiro passo de uma caminhada, que exige um contínuo processo de construção, por meio de ação, reflexão, dinamismo.

A Formação de Professores em âmbito inicial é o ponto primordial para a socialização profissional e a assunção da internalização de princípios, atividades reais e práticas que compõem o fazer da carreira profissional docente. Essa formação deve garantir a aquisição dos saberes da reflexão, da pesquisa e do pensamento crítico relacionados ao fazer docente, vinculando constantemente a produção de conhecimento à dinâmica da integração entre teoria e prática.

Sobre esse aspecto, Cunha (2003) ressalta que a prática quando articulada à pesquisa no processo de formação dos licenciandos dá um novo significado à formação, pois aproxima "o estudante, progressivamente, da totalidade da ação educativa, por meio da atitude investigativa como parceira da condição de aprender". Desloca-se os licenciandos do papel de apenas irem às escolas diagnosticar o que não dá certo e estes passam a atuar como atores da construção de propostas didáticas que tenham relação com as demandas dos sistemas de ensino, assim como, relacionem os conhecimentos estudados com elementos relacionados à gestão escolar e organização dos currículos das escolas.

Considerar a prática como um dos eixos estruturadores do currículo requer também uma análise sobre o modelo de formação vigente em nosso país, visto que será necessário ultrapassar a fragmentação existente no processo de relação entre teoria e prática que ainda predomina nos diferentes cursos de licenciatura das universidades brasileiras. De fato, não é apenas uma questão de opção teórico-metodológica, mas também envolve um processo de tomada de decisão sobre os elementos epistemológicos, com o intuito de se posicionar sobre como serão ultrapassados os limites impostos pela concepção tradicional de conhecimentos, de maneira que a prática auxilie a pensar/analisar elementos do fenômeno educativo estudado, sendo esta permeada por uma fundamentação teórica sólida. 
Nessa perspectiva, na condução da formação de professores observa-se uma significativa tentativa de oferecer de maneira integradora a formação acadêmica, articulada com a rede pública de educação básica. Trata-se de um desafio necessário e importante em razão de duas características peculiares, a saber: primeiro, porque considera e problematiza a realidade local de contextos escolares da educação básica; segundo, porque viabiliza a interlocução entre educação de ensino superior e educação básica, viabilizando as oportunidades de formação e/ou construção de saberes.

Compreendemos que a atuação colaborativa entre escolas e instituições formadoras poderá produzir resultados significativos para os sistemas de ensino, pois, para que os professores que estão em processo de formação venham a atender as demandas cada vez maiores em relação à realização de seu trabalho, faz-se necessário que em seu percurso formativo sejam preparados para enfrentar as exigências de sua profissão e uma das estratégias poderá ser a pesquisa sobre as práticas pedagógicas, desde que haja um planejamento criterioso por parte dos formadores.

Se a formação tem como um de seus propósitos melhorar a qualidade do trabalho desenvolvido na escola por seus agentes educativos, é imprescindível que eles oportunizem, constantemente, uma reflexão sobre os problemas existentes na escola como forma de estimulá-los a organizar meios capazes de ultrapassar esses problemas e avaliar as estratégias de atuação.

Dessa forma, as escolas parceiras traduzir-se-ão em potenciais espaços para o redimensionamento da práxis dos professores-alunos do Curso da Licenciatura, bem como para seus professores ministrantes, contribuindo para o avanço das práticas de formação de professores, sobretudo em função de proporcionar a compreensão estrutural e contínua da formação docente, a interdependência dos conteúdos, sua significação e a organização do fazer pedagógico realizado no chão dessas escolas.

\section{Reflexões sobre o PIBID na Licenciatura em Informática}

É imprenscindível compreender a relevância da formação inicial dos professores em nível de graduação, pois os licenciandos têm a oportunidade de confrontar os conhecimentos pedagógicos de sua formação e refletir sobre a prática docente em situações reais de aprendizagem.

Alguns trabalhos relatam as experiências dos licenciandos em Informática nas escolas públicas por meio do PIBID. Almeida e Carvalho (2012) descrevem a experiência do IFSULDEMINAS, Campus Machado, articulando os programas de Matemática e Computação do PIBID com o tema "Sem Matemática não existe Computação", frisando a importância da articulação dos licenciandos com os professores em efetivo exercício no magistério, baseado nos aspectos pedagógicos e sociais existentes na realidade das escolas públicas. Gaspar et al. (2013) relatam a experiência com o PIBID na formação inicial e na permanência dos licenciados dos Institutos Federais de Minas Gerais na área da Computação, fazendo um recorte temporal de 2009 a 2013, traçando um histórico sobre a criação do PIBID, uma análise de trabalhos correlatos e considerações a respeito das estratégias utilizadas para consolidação dos processos de ensinar e aprender.

Quando se trata da atuação do profissional da Informática, é necessário considerar que dependendo da forma como o computador está presente na escola e na sala de aula, ele pode ser usado apenas para a instrução técnica dos alunos, para 
diminuir o analfabetismo computacional, em que a Informática seria uma disciplina isolada das outras, ou pode ser uma nova forma de ensinar por meio dos potenciais e diversas habilidades que ele pode oferecer. Por consequência, pode-se pensar no ensino da Informática articulado com várias disciplinas potencializando a prática pedagógica de vários professores. Faz-necessário refletir sobre o ensino da Informática nas escolas públicas, que muitas vezes possuem computadores, mas não contam com a ação humana pedagógica que sistematize conhecimentos na área de Informática. Segundo Valente e Almeida (1997), torna-se claro que a promoção dessas mudanças pedagógicas não depende simplesmente da instalação dos computadores nas escolas, como vem sendo vivenciado até o momento.

Para a vivência de ações docentes que envolvam conhecimentos na área da Informática, Lopes (2002) apresenta a figura do coordenador de Informática como possível profissional articulador dos professores à utilização do laboratório de Informática no cotidiano de suas aulas. Para ele, o coordenador não deve ter apenas uma formação técnica, mas sim um envolvimento com o processo pedagógico, justificando a possível relevância do Licenciado em Informática na escola pública. Nesse caso, reconfigura a função do profissional da Informática não apenas como facilitador, mas como coordenador e mediador do processo. É imprenscindível perceber que a formação desse possível coordenador de laboratório deve contemplar o conhecimento sobre as teorias pedagógicas, bem como conhecimentos específicos da área de Informática para articular e gerenciar o processo didático, de modo a buscar os recursos apropriados ao ensino-aprendizagem e mobilizar os professores. Esse profissional está sendo formado nas universidades pelo país. Contudo, apesar da necessidade do professor de Informática nas escolas públicas, a realidade atual mostra que os profissionais formados em licenciatura na área de Informática concorrem no mercado com graduados de diversas outras áreas da Informática ou até técnicos, como dizem Bezerra e Silveira (2011, p. 1):

[...] os quais não raramente se vêem disputando vagas no mercado com profissionais de diversas outras formações, muitas vezes não adequadas. Junte-se isso ao fato dos setores de mercado, quer na esfera pública ou privada, em geral desconhecerem o perfil de um egresso em Licenciatura em Computação, os objetivos do curso, ou mesmo a sua própria existência, chega-se em um cenário onde o egresso não encontra espaço adequado de atuação.

Nos dias atuais, o que vem sendo articulado na escola pública é apenas a liberação de verbas governamentais (inclusive programas) para a montagem do laboratório de Informática, sem grande esforços em definir e instituir um profissional responsável por articular as ações docentes nesse espaço. A escola pública, em diversas situações, utiliza esse espaço como ambiente de consulta e pesquisas na Internet, quando os alunos chegam a ter acesso. Prolifera-se uma concepção inadequada em que apenas a presença do laboratório supre as necessidade de inclusão digital que todos os segmentos da comunidade escolar necessitam. Com isso, Quiles (2009, p. 5268) é esclarecedor quando afirma que:

É importante ressaltar que o acesso às tecnologias da informação e comunicação (TIC's) não acontece simplesmente com a instalação dos computadores na escola, nesse espaço diferenciado, mas se dá a partir da 
necessidade de mediação de professores para trabalhar, acessar e interagir com essas tecnologias no cotidiano da escola. É preciso avançar para além da simples implementação técnica de computadores entendendo como as relações didático-pedagógicas acontecem nesse novo espaço pedagógico.

Pode-se dizer que apesar da inclusão de equipamentos e construção dos laboratórios, pouco vem se avançando no que concerne a formação de professores para concretizar ações pedagógicas favoráveis à inserção da tecnologia no processo educativo. Ainda há muito o que a fazer para que o espaço da Informática seja realmente vivenciado na Escola Pública. Há a necessidade de obrigadatoriedade de um profissional para articular as ações. Neste trabalho, defende-se a presença do Licenciado em Informática, que possui uma formação abrangente para atuar nessa realidade e que pode modificar o atual quadro da utilização dos laboratórios de Informática na escola pública.

Nos estudos para compreender a realidade da atuação do licenciado em Informática na escola, entende-se ainda a importância de que os futuros docentes, mesmo em nível de graduação, têm a possibilidade de aprender na própria prática docente por meio do PIBID. Nesse caso, a formação de professores desde a graduação deve colocar o docente em situações concretas de aprendizagem.

\section{O PIBID e a Licenciatura em Informática: Sistematização das Ações na Concretude Real}

No Campus Natal - Zona Norte do IFRN, o PIBID foi inserido no curso de Licenciatura em Informática no ano de 2012. O subprojeto atual, que se iniciou em março de 2014, conta com a coordenação de dois professores do Curso de Licenciatura, 30 alunos bolsistas de iniciação à docência e três professores supervisores, sendo um em cada escola participante do projeto. Foram selecionadas três escolas públicas da esfera estadual, todas localizadas na Zona Norte de Natal - RN. São elas: a Escola Estadual Professora Ana Júlia de Carvalho Mousinho, a Escola Estadual Walter Duarte Pereira e a Escola Estadual Professor Antônio Fagundes.

As atividades dos alunos no PIBID são todas realizadas nas escolas, sendo no IFRN apenas as reuniões com os coordenadores de área. Os bolsistas estão matriculados do $2^{\circ}$ ao $7^{\circ}$ período do curso e exercem suas atividades nas escolas em horários de acordo com sua disponibilidade, considerando seus horários de aula e atividades pessoais.

\subsection{Ações Iniciais de Formação dos Licenciandos em Informática}

O início das atividades do PIBID se deu com reuniões entre coordenadores de área, supervisores e alunos no Campus Natal - Zona Norte do IFRN, e também nos laboratórios de Informática das escolas. Essas primeiras reuniões tiveram como objetivo apresentar o programa (origem, importância, objetivos e metodologia de trabalho) e os servidores envolvidos. Os alunos selecionados foram divididos entre as três escolas participantes do projeto.

De acordo com as primeiras reuniões realizadas com os supervisores, foi verificado que em nenhuma das três escolas há um profissional qualificado na área de Informática (licenciado ou bacharel) para coordenar ações que visem contribuir para incluir a tecnologia na formação dos estudantes. Considerando isso e para que houvesse 
uma contribuição efetiva dos licenciandos em Informática, tornou-se necessária uma fase de diagnóstico da escola de forma geral, assim como do seu laboratório de Informática, no que se refere a problemas de infraestrutura, mau uso dos equipamentos, instalações inadequadas, horários de disponibilidade, acesso à Internet, dentre outros.

Em cada escola, foram realizados três diagnósticos: organização e gestão escolar, infraestrutura e softwares. Para essa etapa, os alunos foram divididos em três grupos, sendo cada um deles responsável por um diagnóstico. Esta etapa foi concluída com a entrega de cada diagnóstico em forma de relatório para os coordenadores de área e uma apresentação resumida dos resultados para todos os demais bolsistas em reunião previamente agendada.

\subsection{Diagnóstico da Organização e Gestão Escolar}

Esse diagnóstico foi solicitado aos bolsistas para coletar informações relativas a organização e gestão da escola, pois entende-se a necessidade do docente, mesmo em formação inicial, em compreender que as ações docentes ultrapassam as atividades presentes na sala de aula. Nesse diagnóstico foram contempladas condições materiais e imateriais, considerando a forma como o espaço escolar está organizado (número de salas de aula, banheiros, salas de gestão, espaços pedagógicos, secretaria, sala de apoio e salas ociosas) e as condições de funcionamento, bem como a história, símbolos, importância na comunidade, identidade da escola e situação socioeconômica dos discentes.

Além disso, explorou-se a concepção de gestão defendida pela escola, no sentido de compreender como a organização da escola é conduzida por meio de sua legislação, documentos oficiais, projetos e processos decisórios juntos aos órgãos colegiados. Nesse caso, o diagnóstico tem como objetivo permitir que o aluno compreenda a necessidade de conhecer o contexto a qual a escola está inserida em uma dimensão mais ampla.

\subsection{Diagnóstico de Infraestrutura do Laboratório de Informática}

O diagnóstico de infraestrutura consistiu na descrição completa dos aspectos físicos de cada laboratório de Informática: estrutura de hardware (quantidade, configurações e problemas encontrados nos computadores), presença de materiais didáticos (projetor multimídia, quadro branco, mesa e computador para o professor, aparelhos eletrônicos, etc), layout (distribuição de bancadas, computadores e material didático), e estrutura elétrica e de dados (cabeamento, instalação elétrica, acesso à Internet, etc). Com esse diagnóstico, foi possível avaliar as condições reais de cada laboratório para a oferta de cursos, oficinas e treinamentos para estudantes e servidores da escola, assim como para contribuir de alguma forma com o uso mais adequado do mesmo.

Com os problemas detectados, supervisores e coordenadores se articularam para minimizar os problemas encontrados, seja reparando os periféricos com problema, adequando o cabeamento e alterando o layout para melhor uso do laboratório.

\subsection{Diagnóstico de Softwares}

O diagnóstico de softwares consistiu na descrição de todos os programas instalados nos computadores dos laboratórios de cada escola. Essa etapa é fundamental, pois é necessário conhecer todas as possibilidades que o sistema operacional instalado nos 
computadores oferece para a realização das etapas seguintes. Foi solicitado aos alunos que verificassem e analisassem a possibilidade de instalação de novos softwares, a necessidade de upgrade do hardware para a execução rápida e eficiente dos programas e a versão e funcionalidade de cada software instalado.

Em todas as três escolas, o sistema operacional instalado nos computadores é o Linux Educacional [UFPR 2014]. A utilização desse sistema é um projeto do Governo Federal que busca o melhor aproveitamento dos ambientes de Informática nas escolas.

Oferecer cursos relacionados às ferramentas do Linux Educacional, como softwares educacionais e aplicativos utilizados em rede, é uma das possíveis etapas a serem realizadas pelos alunos bolsistas do PIBID, já que a grande maioria dos alunos e servidores das escolas envolvidas no programa não se sentem familiarizados com esse sistema operacional.

\subsection{Planejamento e Oferta de Cursos e Oficinas}

Após os primeiros meses de atuação no PIBID, os alunos passaram a conhecer melhor os servidores e as condições de trabalho em cada escola, e assim podem planejar as próximas etapas conhecendo as dificuldades a serem superadas e podendo verificar como os conhecimentos adquiridos no curso de licenciatura podem ser aplicados. A fase seguinte consiste em propor, articular e providenciar melhorias para os laboratórios, tanto em aspectos de infraestrutura física como lógica, que possibilitem o início das atividades práticas de todos os bolsistas. Esta fase é completamente acompanhada pelos respectivos supervisores, que os instruem sobre o que pode e o que não pode ser viabilizado e os orientam nas dúvidas sobre possíveis melhorias e necessidades de cada laboratório. O papel dos coordenadores de área é fundamental nessa etapa, já que diversos procedimentos técnicos necessários precisam ser realizados de maneira correta e cuidadosa. Alguns dos bolsistas ainda estão no início da graduação e ainda carecem de alguns conhecimentos mais complexos da informática.

Já conhecendo os laboratórios, a fase seguinte consiste em fazer um levantamento das necessidades e das possibilidades de oferta de cursos, oficinas e treinamentos para estudantes e servidores de cada escola. Esse trabalho é feito pelos alunos juntamente com os supervisores, que irão sugerir temas, horários, público-alvo e ideias, para que os alunos possam realizar as ações de inclusão digital e ensino de Informática nas escolas. A ideia é ofertar cursos básicos de Informática para alunos e capacitação em ferramentas que possam auxiliar os professores de cada escola em suas aulas. Para as ofertas de cursos e oficinas, os alunos serão divididos em duplas. Cada dupla irá preparar e adequar todo o material do curso sob a orientação dos coordenadores de área.

\section{Considerações Finais}

A formação dos professores ao longo dos anos é um grande desafio a ser superado. A implantação do PIBID, com foco na formação inicial dos professores, vem tentando impulsionar experiências exitosas logo nos primeiros anos dos cursos de licenciatura. Nessa perspectiva, permite-se a vivência de novos processos formativos aos licenciandos, que até bem pouco tempo só teriam oportunidade de inserção na escola pública nos últimos períodos dos seus cursos. Defende-se neste trabalho então uma formação que contemple a possibilidade de integrar as necessidades de vivências 
relativas à docência por parte dos licenciandos, bem como um processo inicial de mobilização dos laboratórios na escola pública.

Nas vivências realizadas pelos bolsistas do PIBID do Curso da Licenciatura em Informática do Campus Natal - Zona Norte do IFRN, percebe-se significativas mudanças no que concerne a formação dos licenciandos, que podem conduzir de maneira real as experiências da docência, articulando com os fundamentos teóricos discutidos no curso. Além disso, as escolas públicas parceiras do PIBID percebem a transformação social dos espaços dos laboratórios, pois eram espaços ociosos ou mesmo sem um trabalho significativo que promovesse a integração de práticas pedagógicas e técnicas computacionais. Para a escola pública foi significativo, ainda, a relevância dos diagnósticos realizados, pois promoveu-se a percepção dos impasses que comprometem o uso dos laboratórios, bem como o reconhecimento do potencial de uso desses espaços de aprendizagem, e não apenas de consulta.

Assim, pode-se dizer que, no PIBID da Licenciatura em Informática, tenta-se vivenciar práticas que não permitam apenas aquisição somatória da Informática e da Educação, e sim a integração das duas áreas. Nesse caso, a formação deve:

\section{[...] prover condições para que ele construa conhecimento sobre as técnicas computacionais, entenda por que e como integrar o computador na sua prática pedagógica e seja capaz de superar barreiras de ordem administrativa e pedagógica [Valente e Almeida 1997, p. 25].}

A constituição dos saberes docentes deve ser a busca central do PIBID, mesmo com os impasses vivenciados com a ausência do profissional da Informática na escola pública. Apesar disso, percebe-se a relevância do programa na formação inicial de professores, que vem promover a constituição de uma prática pedagógica que articule os conhecimentos teóricos e técnicos necessários ao licenciando em Informática.

\section{Referências}

Almeida, C. C. e Carvalho, L. P. A formação de professores no curso de Licenciatura em Computação: um relato das práticas educacionais de iniciação a docência. Anais do XVIII Workshop de Informática na Escola. ISSN 2316-6541. Rio de Janeiro: SBC, 2012.

Bezerra, L. N. e Silveira, I. F. Licenciatura em Computação no Estado de São Paulo: uma Análise Contextualizada e um Estudo de Caso. XIX Workshop sobre o Ensino de Computação. Anais do CSBC 2011. Natal: SBC, 2011.

Brasil, Ministério da Educação, Conselho Nacional de Educação. Portaria n. 72, de 9 de abril de 2010. Disponível em: <http://www.capes.gov.br/>. Acesso em: 17 mai. 2014.

Brasil, Ministério da Educação, Conselho Nacional de Educação. Portaria No 096, de 18 de Julho de 2013.2 Disponível: http://www.capes.gov.br/images/stories/download/legislacao/Portaria_096_18jul13_ AprovaRegulamentoPIBID.pdf. Acesso em: 17 mai. 2014.

Canan, S. R. PIBID: promoção e valorização da formação docente no âmbito da Política Nacional de Formação de Professores. Rev. Form. Doc., Belo Horizonte, v. 04, n. 06, 
p. 24-43, jan./jul. 2012. Disponível em http://formacaodocente.autenticaeditora.com.br. Acesso em: 17 mai. 2014.

Cunha, M. I. Formação de professores e currículo no ensino superior: reflexões sobre o campo político-epistemológico. In: Moraes, Maria Célia; Pacheco, José Augusto; Evangelista, Maria Olinda (Orgs.). Formação de professores: perspectivas educacionais e curriculares. Porto: Porto Editora, 2003.

Gaspar, M. L., Ribeiro, E. A. e Silva, K. G. O ensino da Computação, o PIBID e a formação inicial: primeiras aproximações com o objeto de estudo. Anais do II Colóquio Nacional - A Produção do Conhecimento em Educação Profissional. Natal: IFRN, 2013.

IFRN: Instituto Federal de Educação, Ciência e Tecnologia do Rio Grande do Norte. Projeto Pedagógico do Curso Superior de Licenciatura em Informática na Modalidade Presencial, 2012. http://portal.irn.edu.br. Acessado em Abril/2014.

Lopes, J. J. A introdução da informática no ambiente escolar, 2002. Disponível em: http://www.clubedoprofessor.com.br/artigos/artigojunio.htm. Acesso em: Abril de 2013.

Quiles, C. N. S. O Uso do Computador na Escola: Mapeando os "Modos de Ensinar" na Sala de Tecnologias Educacionais (STE). Anais do IX Congresso Nacional de Educação. Paraná, PUCPR, 2009.

UFPR: Universidade Federal do Paraná. Linux Educacional 5.0. Disponível em: http://linuxeducacional.c3sl.ufpr.br/. Acesso em Maio de 2014.

Valente, J. A. e Almeida, F. J. Visão Analítica as Informática no Brasil: a questão da formação do professor. In: Revista Brasileira de Informática na Educação, Florianópolis, v. 1, 1997. 